\title{
EL IMPUESTO DE RENTA EN COLOMBIA: UNA MIRADA DESDE EL GASTO TRIBUTARIO*
}

\author{
INCOME TAX IN COLOMBIA: A VIEW FROM TAX \\ EXPENDITURE
}

\section{Lucía del Carmen Bolaños BolaÑOs**}

RESUMEN: Este artículo busca evidenciar la inestabilidad jurídica del impuesto de renta en Colombia, su efecto negativo en la confianza, la legalidad y la equidad del sistema tributario, y la consecuente inequitativa distribución de la carga tributaria. Para ello aborda de manera general la evolución del impuesto desde 1918 a 2018, describe la estructura actual, tanto para las personas naturales como las jurídicas, analiza aspectos jurídicos relevantes derivados de la aplicación del marco tributario en perspectiva de los beneficios tributarios y el costo fiscal según el análisis de los informes presentados por la UAE DIAN entre 2004 y 2018, advirtiendo cómo el gasto tributario ha fragmentado los principios de justicia tributaria en Colombia, impregnando de un halo de injusticia no solo a la imposición, sino al sistema tributario en conjunto.

Palabras clave: impuesto de renta, inestabilidad jurídica, beneficios tributarios, costo fiscal.
ABSTRACT: This article seeks to demonstrate the legal instability of income tax in Colombia, its negative effect on legality and equity of the tax system and the consequent inequitable distribution of tax burdens. It deals in a general way with the evolution of income tax from 1918 to 2018, it describes the current structure for both natural and legal persons, it analyses some relevant legal aspects arising from the application of the tax framework from the perspective of tax benefits and the fiscal cost according to the reports submitted by UAE DIAN in 2004 to 2018, warning how tax spending has fragmented the principles of tax justice in Colombia, imbuing not only taxation but the tax system a whole with an halo of injustice.

Keywords: Income Tax, Legal Instability, Tax Benefits, Tax Cost.

* Artículo recibido el 6 de octubre de 2017 y aceptado para su publicación el 28 de abril de 2019.

** ORCID: 0000-0003-1454-4554. Doctora en Derecho por la Universidad Autónoma de Chile, doctora en Derecho y Ciencias Políticas por la Universidad de Barcelona; abogada, magister y especialista por la Universidad Libre de Cali; contadora pública por la Universidad del Valle. Investigadora en el Grupo de Sistemas Penitenciarios y Carcelarios (A1) (Cali, Colombia).Correo electrónico: lucia.bolanos@outlook.com.

Boletín Mexicano de Derecho Comparado, nueva serie, año LI, núm. 155, mayo-agosto de 2019, pp. 721-756.

Esta obra está bajo una Licencia Creative Commons Atribución-NoComercial-SinDerivar 4.0 Internacional, IIJ-UNAM. 
SUMARIO: I. Evolución histórica del impuesto de renta en Colombia. II. Estructura del impuesto sobre la renta. III. El impuesto de renta y el gasto tributario. IV. Conclusiones. V. Bibliografia.

\section{EVOLUGIÓN HISTÓRICA DEL IMPUESTO DE RENTA EN COLOMBIA}

En 1918 con la Ley 56 se estableció el impuesto de renta en Colombia, desde entonces y hasta hoy múltiples reformas tributarias hacen parte del cambio de forma de esta imposición, pues su transformación no ha sido propiamente una evolución en sentido estricto, sino más bien, una mutación al compás del trastabillar de las necesidades financieras del gobierno en turno. Así, se han creado, modificado y eliminado una serie de disposiciones normativas, orientadas a cambiar los elementos estructurales de la imposición, reclasificando los sujetos pasivos para dar cabida a nuevos contribuyentes o para exonerar a otros; ampliando la gama de hechos generadores o eliminando algunos, para crear, modificar o eliminar beneficios tributarios orientados a incentivar unos sectores específicos, compensar o solventar las necesidades de algunas regiones, o, disminuir o aumentar la tarifa; en todo caso la producción normativa parece moverse en una avalancha de buenas intenciones políticas, jurídicas, sociales y económicas, pero que distantes de conseguir los resultados buscados han causado un universo normativo enrevesado, impregnando de ineficiencia el recaudo, aumentando el gasto tributario y consecuentemente desbalanceando la distribución de la carga tributaria.

Los históricos y constantes cambios normativos a esta exacción, lejos de perfilarse como verdaderas transformaciones tributarias encaminadas a un impuesto con mayor grado de progresividad, equidad y justicia, lo han fragmentado y enmarañado en una especie de aleación normativa, impregnando la imposición y el sistema tributario en conjunto, con un halo de injusticia tributaria, de ello da cuenta su historia.

Así, en una mirada general se encuentra que la primera modificación se dio por medio de la Ley 64 de 1927, organizándolo en un esquema cedular, con tarifas diferenciales según el origen de la renta que oscilaban entre el 1\% al 8\%; hacia 1935 se modificó la ley, reasignando una tarifa del $17 \%$, representando para entonces el $27 \%$ de los ingresos del fisco nacional (Restrepo, 2012: 111). Desde 1974, Colombia recibió distintas misiones 
internacionales conformadas por profesionales en distintas áreas para que realizaran estudios analíticos orientados a la construcción de informes y recomendaciones para el mejoramiento de las condiciones del país.

Así, entre 1974 y 1986 se reciben las primeras misiones, la de Richard Musgrave y la misión Taylor, coincidentes en sugerir un incremento de los ingresos fiscales por medio de reformas tributarias que permitieran cubrir el déficit fiscal ascendente a 3.5 billones de pesos, producto de los mayores gastos y el menor recaudo en caja. Los informes evidenciaron que la media de la carga tributaria colombiana alcanzaba $11.5 \%$ del producto interno bruto (PIB), cifra que comparativamente con la media latinoamericana se ubicaba en 8.5 puntos porcentuales por debajo, en consecuencia, se propuso unificar la tasa de tributación en un intervalo del 40 al 45\% para todos los tipos de sociedades, manteniendo los incentivos tributarios a las exportaciones, sin implementarlos para las inversiones (Junguito y Rincón, 2004: 67). Con la Ley 49 de 1975, la tasa de renta se fija en 40\% para las sociedades anónimas y 20\% para las limitadas, se incorpora el gravamen a las ganancias ocasionales y la renta presuntiva mínima sobre el patrimonio líquido con una tarifa de 8\% (Junguito y Rincón, 2004: 68-73); era sin duda un nuevo panorama fiscal, con el cual se buscaba solventar total o parcialmente el déficit fiscal, pero el cometido no se logró. Se destaca que Colombia en ese entonces era el primer país en tributación directa y el último en indirecta dentro de los países latinoamericanos, ${ }^{1}$ distribución que en materia fiscal incide directamente en el mayor o menor grado de progresividad o regresividad, equidad y justicia del sistema tributario.

La tercera misión, la de Bird-Wiesner, llega entre 1978 y 1981, recomendando mejorar la administración tributaria para reducir la evasión, fortalecer las herramientas de cobro, extender los mecanismos de retención e intensificar la auditoría. De 1980 a 1990, el excesivo endeudamiento externo no era sostenible con los recaudos tributarios, situación que presionó hacia una reforma general del impuesto a la renta a través de la Ley 14 de 1983. En 1985 el desequilibrio financiero continúa por lo que se emite la Ley 50, que obliga la suscripción de bonos forzosos subsidiados como sobretasa del impuesto de renta. En 1986 la Ley 75 amplió la base gravable del impuesto a la renta y redujo las tarifas, señalando un límite máximo del $30 \%$ para las personas naturales, esta misma tarifa se unifica para las

1 En las estadísticas se compararon países como Brasil, Chile y Argentina. 
personas jurídicas, se da exención parcial a los rendimientos financieros y se establece la no deducibilidad del componente inflacionario (Junguito y Rincón, 2004: 84-89).

De 1990 a 2003, periodo caracterizado por los altibajos de la economía colombiana manifestados en crecimiento económico y el déficit fiscal (Echavarría, 2001: 141-142), se da uno de los hechos más importantes para cualquier país de corte democrático, la promulgación de una nueva Constitución política, por medio de la cual, Colombia pasó a ser un Estado social de derecho, cambio de Estado que conllevó a una serie de compromisos en materia social que debían ser cubiertos con más recursos, afectando directamente el incremento del gasto público y consecuentemente el deterioro de las finanzas, desbalanceando aún más las finanzas públicas, aumentando el déficit fiscal.

En este contexto, el gobierno estaba presionado a la consecución de nuevas fuentes de financiación y, en consecuencia, se generaron variadas modificaciones tributarias. ${ }^{2}$ Una de ellas, la Ley 223 de 1995, de Racionalización Tributaria, la cual estabilizó la tasa del impuesto de renta y complementarios en un 35\% para las sociedades, disminuyó las tarifas marginales para las personas naturales y modificó la renta presuntiva para los grandes contribuyentes con tarifa del 1.5\% sobre el patrimonio líquido o 5\% sobre el patrimonio bruto (Calderón y González, 2002: 12-13), adicionalmente, se reglamentó por el Decreto 782 de 1996, retenciones en la fuente; fue una transformación del régimen fiscal que se esperaba fuera a largo plazo, pero nuevamente ello no ocurrió.

En 2000, con un presupuesto desfinanciado, el gobierno buscó la provisión de recursos cercanos a 3.8 billones de pesos e introdujo una nueva reforma tributaria con la Ley 633 (Calderón y González, 2002: 105), modificando la renta presuntiva a una tasa del $6 \%$, estableciendo deducciones del $125 \%$ por donaciones para desarrollo tecnológico y científico, y de un $60 \%$ a instituciones educativas avaladas por el Ministerio de Educación

2 Las reformas tributarias realizadas a partir de la promulgación de la Constitución política de 1991 han fincado su objetivo en la consecución de más ingresos para la realización de este Estado constitucional. Sin embargo, es cuestionable el medio, en tanto el gobierno se ha centrado en el incremento de ingresos vía reformas tributarias de carácter regresivo, cuyo eje ha orbitado sobre el incremento efectivo de la tributación a través de impuestos indirectos, más que en los indirectos, situación que en poco o nada contribuye a la justicia y equidad que persigue un Estado social y democrático de derecho (López et al., 2011).

Esta obra está bajo una Licencia Creative Commons

Atribución-NoComercial-SinDerivar 4.0 Internacional, IIJ-UNAM.

Boletín Mexicano de Derecho Comparado, núm. 155, mayo-agosto de 2019, pp. 721-756. 
Nacional (MEN), beneficios tributarios que sí aminoraron los recaudos fiscales, pero no incentivaron los sectores relacionados.

En 2002, la Ley 782 modificó el límite de las rentas exentas paulatinamente decrecientes del $70 \%$ al $0 \%$ entre 2003 y 2006, se incluyó una sobretasa al impuesto del $5 \%$ en 2002 y del $10 \%$ en 2004. En 2003, la Ley 863 incrementó la tasa del 35\% al 38.5\%, se creó una tasa del 5\% para la declaración de activos omitidos y se permitió una deducción del $30 \%$ por inversión en activos fijos productivos. En 2005, con la Ley 1004 de $2005^{3}$ se crean las zonas francas, como territorios geográficos especiales dentro del territorio nacional donde se desarrollarán actividades industriales de bienes, servicios o comerciales, importación y exportación, que tendrían tratamiento tributario diferenciado, comenzando por la tarifa que se fija en un 15\% de acuerdo con el artículo 240.1. del Estatuto Tributario (ET). En 2006, la Ley 1111 disminuyó la renta presuntiva a una tasa del 3\%, y modificó las tarifas marginales entre el $0 \%$ y el 33\% para las personas naturales.

En 2012, el gobierno persigue una reforma tributaria estructural y propone la Ley $1607,{ }^{4}$ la cual transformó completamente todo el régimen tributario. Para efectos del impuesto sobre la renta, creó un nuevo impuesto complementario al primero, Impuesto a la Renta para la Equidad (CREE) con una tasa del 9\%; redujo la tasa del impuesto a la renta al $25 \%$ para las sociedades y a un $10 \%$ para ganancias ocasionales. En el régimen para las personas naturales, estableció un nuevo universo de contribuyentes a través de categorías clasificatorias de los sujetos pasivos: i) asalariados; ii) trabajadores por cuenta propia, y iii) otros, de acuerdo a esta clasificación se fijaron sistemas de depuración de la renta alternos al régimen ordinario: i) Impuesto Mínimo Alternativo Nacional (IMAN), y ii) Impuesto Mínimo Alternativo Simple (IMAS), que en cualquiera de los casos se liquidaban a tasas marginales diferentes; estos cambios normativos, entre otros, no fueron claros, generaron confusión entre los contribuyentes, quienes interpusieron variadas demandas de inconstitucionalidad por violación a principios tributarios constitucionales como la progresividad, equidad, igualdad y justicia.

3 Ley 1004, por la cual se modifica un régimen especial para estimular la inversión y se dictan otras disposiciones. Diario Oficial núm. 46138 del 31 de diciembre de 2005.

4 Ley 1607, por la cual se expiden normas en materia tributaria y se dictan otras disposiciones. Diario Oficial núm. 48655 del 26 de diciembre de 2012. 
Pero la dinámica del cambio no paró, y en 2014, nuevamente con la Ley $1739,{ }^{5}$ se incorporaron modificaciones, entre ellas: $i$ ) el impuesto a la riqueza para patrimonios superiores a mil millones, con tarifas marginales del $0.20 \%$ al $1.15 \%$ para personas jurídicas, y $0.125 \%$ al $1.5 \%$ para personas naturales; ii) la sobretasa al CREE con un mínimo exento y tarifa marginal en un rango del $0 \%$ al 5\%, y iii) se creó el impuesto a la normalización tributaria. Adicionalmente el artículo 44 creó la Comisión de Estudio al Sistema Tributario Colombiano y dispuso su conformación pasados dos meses de la entrada en vigor de la Ley. El gobierno pretendía lograr mayores ingresos fiscales, vía impuesto al patrimonio y la normalización de activos no declarados en años anteriores, pero el objetivo se consiguió solo en parte y el desbalance financiero siguió.

Como se advierte, la variabilidad jurídica tributaria en Colombia ha sido una constante; las mal llamadas reformas tributarias estructurales solo han sido un tapiz para dar respuesta a las necesidades financieras presupuestales, dejando de lado casi por completo la función redistributiva de los impuestos; la crítica ha sido constante y el gobierno trató de responder a ella en 2015 con la conformación de la Comisión de Expertos para la Equidad Tributaria (CEET), ${ }^{6}$ cuyo objetivo sería el análisis propositivo en la configuración de un mejor sistema tributario, pensado y planeado para el largo plazo. La CEET, tras un análisis, emitió tres informes en 2015, remitidos al ministro de Hacienda y Crédito Público. El primero destacó el crecimiento del gasto público con los compromisos asumidos en la Constitución política de 1991, pasando de menos del 10\% al 19\% en 2013; la existencia de tasas de tributación nominal altas (comparadas internacionalmente), pero con carga tributaria baja, expresada en el recaudo efectivo; la creación de impuestos de carácter transitorio con vocación de permanentes, como el impuesto al patrimonio y el gravamen a los movimientos financieros; planteó la posibilidad de reducción de la brecha de recursos tributarios vía incremento del recaudo, combinado con una disminución de los gastos públicos que no contribuyeran a la equidad y la eficiencia de la economía (CEET, 2015a).

5 Ley 1739, por medio de la cual se modifica el Estatuto Tributario, la Ley 1607 de 2012, se crean mecanismos de lucha contra la evasión y se dictan otras disposiciones. Diario Oficial núm. 49374 del 23 de diciembre de 2014.

6 La CEET fue creada mediante el Decreto 0327/2015 del 27 de febrero. 
En el segundo informe hizo un análisis del Régimen Tributario Especial (RTE), asociaciones, corporaciones, fundaciones y en general las entidades sin ánimo de lucro, resaltando las diversas categorías a las que pueden pertenecer distintos sujetos, pese a integrarse a un mismo grupo, lo que derivaba en obligaciones sustanciales dispares como: i) la obligación de presentar declaración de renta, liquidando el impuesto con una tarifa diferencial del 20\% exclusivamente sobre los excedentes no reinvertidos; ii) presentación de declaración de ingresos y patrimonio no de impuesto a la renta o la no presentación de declaración alguna; iii) la liquidación o no de anticipos e igualmente la renta presuntiva, y iv) la limitación de la retención en la fuente únicamente por actividades industriales, mercadeo y rendimientos financieros. Éstas, entre otras razones, llevan a la CEET a plantear la eliminación del RTE, manteniendo solo un tratamiento especial para los entes territoriales: nación, municipio, distritos, departamentos, territorios indígenas (CEET, 2015b).

El informe final para efectos de impuesto de renta hizo un análisis de la tributación para personas naturales y las sociedades. En el primer caso propuso: i) ampliar la base, incluyendo más personas al sistema; ii) disminuir los beneficios, y iii) simplificar el tributo mediante un mismo tratamiento, estas propuestas implicarían que se eliminen los sistemas alternativos para la liquidación del impuesto IMAN e IMAS, una nueva tabla de tarifas marginales con una máxima del $35 \%$, junto a límites porcentuales, globales y absolutos de los beneficios, aumentar la tarifa del 3 al 4\% en renta presuntiva en aras de eliminar el impuesto al patrimonio, crear tres tarifas para efectos de las ganancias ocasionales, un 10\% para sucesiones y donaciones, $20 \%$ para rifas y juegos de azar, y $15 \%$ para ganancias ocasionales por venta de inmuebles y otros activos, gravar los dividendos como renta gravable ordinaria (CEET, 2015c: 10-13). Para el caso de las sociedades, la CEET sugirió la eliminación del impuesto de renta para la equidad CREE, el impuesto a la riqueza o patrimonio empresarial y la sustitución por un nuevo impuesto, el Impuesto sobre las Utilidades Empresariales, con una tarifa entre el 30 y el 35\%, fijar la renta presuntiva en el 4\% y eliminar los aportes parafiscales sobre la nómina (CEET, 2015c: 12-13).

Sin embargo, las sugerencias no gozaron de buena acogida, entre otras razones por la difícil coyuntura económica marcada por el creciente déficit fiscal, que al 2015, alcanzaba el 3.6\% del PIB, una progresiva dependencia fiscal que representaba el $53 \%$ del presupuesto, un endeudamiento 
externo ascendente que consumía en promedio el 22.5\% del presupuesto, equivalente al 5.8\% del PIB (Ministerio de Hacienda y Crédito Público, 2015: 2-16 [en adelante MHCP]), una perspectiva entrabada de crecimiento económico que no superaba el 2.7\% para 2016 (Fondo Monetario Internacional, 2016: 1 [en adelante FMI]), una inflación creciente con un acumulado anual, a marzo de 2016, de 7.59\% (Banco Central de la República, 2016: 1) un proceso de paz en negociación con defensores y fuertes detractores políticos que implicaría la destinación de recursos para el posconflicto, aunado al reclamo de la sociedad y el sector empresarial por un sistema tributario más simple y una carga tributaria más equilibrada, que no veían con buenos ojos las propuestas planteadas por la CEET. Así, la fuerte presión interna hacia el gobierno hizo que, pese a la conformación de la Comisión, sus tres informes y sugerencias, se postergue cualquier cambio al sistema tributario, por la difícil situación política y la desaprobación del gobierno en general, a ello se sumaron las tensiones externas de organismos multilaterales como el FMI, que públicamente exigieron reformar el sistema tributario colombiano, que, a consideración de expertos analistas económicos y financieros, era inminentemente necesario.

En este entorno, en 2015, y pese a que no se presentó una reforma tributaria, el gobierno sí reafirmó la necesidad de realizar una modificación al sistema tributario en el Plan de Desarrollo Nacional 2014-2018. Así, a través de múltiples compromisos, se demarcó el caminó sobre el cual se erigiría la senda fiscal, al menos para los próximos cuatro años, dentro de éstos compromisos se encontraban: i) alinear las políticas en el ámbito de la competitividad con los principios del Sistema Nacional de Competitividad e Innovación, para el logro de los propósitos, por lo tanto, los beneficios tributarios considerados como una política de competitividad moderna deberían ser horizontales, evitando el problema de captura de rentas y economía política (Departamento Nacional de Planeación, 2015: 111 [en adelante DNP]); ii) racionalizar la regulación para la competitividad empresarial enfocada desde dos componentes, por un lado, la racionalización de trámites, y por otro, las mejores prácticas de producción normativa, se encarga conjuntamente al Ministerio de Industria Comercio y Turismo (MinCit) y la Unidad Administrativa Especial Dirección de Impuestos y Aduanas Nacionales (UAE DIAN), evalúen la efectividad de los instrumentos tributarios en favor del comercio exterior de servicios en pro de las modificaciones a que hubiese lugar (DNP, 2015: 148); iii) para incentivar 
el incremento de inversión en ciencia, tecnología e innovación empresarial, el gobierno afirma que realizará ajustes normativos a los beneficios tributarios: $\left.{ }^{7} i v\right)$ dentro de la política fiscal, hay un compromiso implícito de mantener la regla fiscal. ${ }^{8}$ En cuanto a las medidas que soportan la política fiscal, se hace alusión al alto costo en el cumplimiento de las obligaciones fiscales, foco de desigualdades en la carga tributaria conducente a una mayor evasión y fraude, por lo cual el gobierno se compromete a promover la reducción de los costos de cumplimiento de las obligaciones fiscales, direccionando a las entidades de administración fiscal a políticas de facilitación, simplificación y orientación clara del servicio (DNP, 2015: 996).

Este preámbulo finalmente se concretó fragmentariamente con la Ley 1819 de 2016, ${ }^{9}$ denominada reforma tributaria estructural, norma por medio de la cual se derogó parcialmente la Ley 1739. Dentro de las principales modificaciones en cuanto al impuesto de renta aplicable a personas naturales se modificó el sistema de determinación de renta para las personas naturales, pasando a un sistema de renta cedular basado en cinco cédulas individuales de renta así: a) trabajo; b) pensiones; c) capital; d) laborales, y e) dividendos y participaciones, computando las rentas por período de manera independiente, al igual que la compensación de pérdidas e imputación de rentas no gravadas y exentas, cuya sumatoria total no podría ser superior al $40 \%$, excepto para los funcionarios de relaciones exteriores; ${ }^{10}$

7 El documento no hace mención, si quiera genérica, de los beneficios que se contemplan para tal propósito (DNP, 2015: 164).

8 La Ley 1473 por medio de la cual se establece una regla fiscal y se dictan otras disposiciones (Diario Oficial núm. 48121 del 5 de julio de 2011) introdujo la regla fiscal como un instrumento de preservación de la estabilidad financiera, al tiempo que se aprueba el Acto Legislativo 003 por el cual se establece el principio de sostenibilidad fiscal (Diario Oficial núm. 48117 del 1o. de julio de 2011), modificando el artículo 334 superior, introduciendo el principio de sostenibilidad fiscal, e incidiendo directamente sobre los artículos 339 y 346. Tres preceptos normativos pilares del régimen económico y de la hacienda pública de la Constitución Política de Colombia, mandatos que se sostendrán para lograr aminorar el déficit fiscal estructural del gobierno central del 1.8\% del PIB en 2018 y hasta el 1\% en 2022, de conformidad con el PND (DNP, 2015: 938).

9 Ley 1819 por medio de la cual se adopta una reforma estructural, se fortalecen los mecanismos para la lucha contra la evasión y la elusión fiscal, y se dictan otras disposiciones. Diario Oficial núm. 50101 del 29 de diciembre de 2016.

10 La no aplicación del $40 \%$ como límite a la sumatoria de rentas exentas es una norma repetitiva, dispuesta en el parágrafo único del artículo 336 y el parágrafo 4 del artículo 206.1. Tanto la prima especial como la prima de costo de vida fue creada por medio del 
igualmente eliminó los sistemas alternativos de depuración IMAN e IMAS, de este modo se cambió completamente la determinación del impuesto de renta, en tanto la distinción del impuesto ya no estaría dada por la categoría del contribuyente como lo estableció la Ley 1607, sino la fuente del ingreso que daría cuenta de su naturaleza.

En cuanto al impuesto de renta para las personas jurídicas, se volvió obligatorio el reconocimiento de costos, gastos, activos, pasivos y demás cuentas bajo el nuevo marco normativo adoptado mediante la Ley 1314 de 2009, ello implicaría que los obligados a llevar contabilidad debían aplicar las Normas Internacionales de Información Financiera (NIIF) para la valuación y medición de las partidas contables que son fuente para la determinación del impuesto de renta, hecho que hasta ese momento era potestativo para algunas empresas como las pequeñas y medianas empresas (MiPymes) pertenecientes al grupo dos de implementación. Es importante señalar que tal método de reconocimiento y valuación genera diferencias fiscales transitorias y permanentes, que tienen efecto directo en la determinación del impuesto de renta.

Por otro lado, la tarifa del impuesto de renta pasó del 25\% al 33\% para las empresas nacionales y extranjeras, eliminando la distinción y progresividad tarifaria para unas y otras que había establecido la Ley 1607; a la vez, fijó una tarifa diferencial del 9\%, aplicable para algunas empresas del sector hotelero, editorial y para los rendimientos derivados de la reserva de estabilización de las sociedades administradoras de fondos de pensiones y cesantías, de conformidad con el artículo 240 ET. Igualmente, se suprimió el impuesto de renta para la equidad (CREE) y en su lugar se incluyó una sobretasa sobre el impuesto de renta del 6\% y el 4\% para los años 2017 y 2018, respectivamente. Adicionalmente, derogó el beneficio de progresividad en el impuesto de renta para las MiPymes, aplicable desde 2010, de acuerdo con la Ley 1429, por lo tanto, solo se mantuvo dicho beneficio para las empresas ya acogidas a esta norma.

El actual gobierno (hasta el momento de este escrito) ha presentado al Congreso un proyecto de Ley de Financiamiento con el objetivo de recau-

Decreto 3357 por el cual se dictan normas sobre el Régimen Salarial y Prestacional de los Servidores Públicos Diplomáticos, Consulares y Administrativos del Ministerio de Relaciones Exteriores, y se dictan otras disposiciones (Diario Oficial núm. 47.465 del 7 de septiembre de 2009), y la excepción del límite es aplicable a servidores públicos diplomáticos, consulares y administrativos del Ministerio de Relaciones Exteriores quienes imputarán como renta exenta el $100 \%$ por este concepto.

Esta obra está bajo una Licencia Creative Commons

Atribución-NoComercial-SinDerivar 4.0 Internacional, IIJ-UNAM.

Boletín Mexicano de Derecho Comparado, núm. 155, mayo-agosto de 2019, pp. 721-756. 
dar 14 billones de pesos, necesarios para cubrir los recursos financieros de los programas propuestos y aprobados en el presupuesto para la vigencia 2019, exponiendo teóricamente que dicha ley es necesaria para asegurar la estabilidad financiera a mediano plazo, reducir la carga tributaria al reactivar la economía, alcanzar una mayor progresividad y distribución del ingreso y simplificar el sistema tributario para una mayor formalización (MHCP, 2018: 2). Así, se propone la ampliación de la base del IVA a todos los productos y servicios, excepto salud, educción, transporte, servicios públicos, productos de salud y bienestar, intereses, comisiones, seguros, rendimientos financieros, construcción de obras civiles, edificaciones, arrendamientos, plantaciones, servicios del gobierno, productos del tabaco y servicio doméstico (MHCP, 2018: 1-16). En materia de impuesto sobre la renta para las personas físicas, se cambia el sistema de renta por cédulas retornado al sistema de renta global por depuración ordinaria, unido al incremento de la tarifa que llega hasta un 37\% aplicable a las rentas que superen 1,140 UVT (Unidad de Valor Tributario) (MHCP, 2018: 26-27); para las personas naturales con negocio o pequeños microempresarios, se cambia el monotributo por el impuesto unificado de tributación simple de causación anual y pago bimestral, con tarifas diferenciales para el sector comercio al por mayor y por menor en un rango de $2.6 \%$ hasta $5.6 \%$, servicios profesionales y de consultoría con un $5.6 \%$ al $9.6 \%$, y servicio de restaurante y cafetería con tarifas que van desde el 11.1\% al 13.6\%, según el monto de ingresos brutos anuales (MHCP, 2018: 35-40).

En cuanto al régimen para las sociedades y empresas de mayor tamaño, ${ }^{11}$ se retorna a los beneficios de los contratos de estabilidad jurídica para las mega inversiones, consistente en garantizar una serie de beneficios tributarios por el término de duración del contrato (MHCP, 2018: 35-40), modalidad que ya había sido instituida por medio de la Ley 963 de 2005, ${ }^{12}$ pero que fue desmontada por las diversas controversias, por un lado, de tipo jurídico en razón de la inequidad y desigualdad tributaria, y por otro, de tipo económico en razón de las posibles distorsiones en la economía, aunado a la incertidumbre de la efectividad del incremento de la inversión reflejado en inversión real, innovación y productividad. Adicionalmente,

11 Entiéndase "mayor tamaño" en términos de ingresos devengados, patrimonio bruto o generación de rentas.

12 Ley 963, por la cual se instaura una ley de estabilidad jurídica para los inversionistas en Colombia. Diario Oficial núm. 45963 del 8 de julio de 2005. 
se reforman la deducción en impuestos pagados a un 50\% para impuesto de industria y comercio y el gravamen a los movimientos financieros, se reincorpora un descuento del 100\% de impuestos tasas y contribuciones pagados y relacionados directamente con el giro ordinario del negocio; por otra parte, se fija como descontable el 100\% del IVA en la importación, formación y construcción de activos fijos (MHCP, 2018: 52).

Para efectos de la renta presuntiva, se presume que la renta líquida no será inferior al 3.5\% del patrimonio líquido, pero decrecerá paulatinamente a un $3 \%$ en $2019,1.5 \%$ en 2020 y $0 \%$ en $2021 .^{13}$

Se incorpora un régimen de rentas exentas para las empresas de economía naranja que se dediquen a una lista taxativa de actividades y que cumplan con un número no inferior a diez empleados, un monto mínimo de inversión de 25,000 UVT manteniéndolo por tres años, el tratamiento diferencial será por un período de cinco años; para empresas del sector rural el período será de diez años, con un monto mínimo de inversión de 50,000 UVT sostenida por un período de seis años; para las empresas generadoras de energía alternativa, el término será de quince años, siempre que tramiten, obtengan y vendan certificados de emisión de bióxido de carbono, según el protocolo de Kyoto, unido a que un 50\% de los ingresos derivados de su comercialización sean destinados a obras de beneficio social en la región donde opere el generador (MHCP, 2018: 52-57).

Finalmente, la tarifa para las personas jurídicas, aplicable a sociedades nacionales y asimiladas, será decreciente pasando de un 33\% en 2019 a un $30 \%$ en 2022; para el sector hotelero las rentas pasaron de ser exentas a ser rentas gravadas con una tarifa del 9\%. Estos son algunos de los cambios más relevantes que traerá la ley de financiamiento, de ser aprobada.

Como se evidencia, el conjunto de normas tributarias en Colombia se ha caracterizado por una metamorfosis camaleónica, que va de tumbo en tumbo, sometiendo a las personas naturales y los empresarios a una especie de laboratorio fiscal, por medio de normas con apariencia de permanentes, pero con vocación claramente transitoria, o la inversa, con normas incorporadas como transitorias, pero con clara inclinación de permanentes; con un eje común en ambos casos, su trascendencia en el tiempo ha

13 Los contribuyentes acogidos al régimen unificado de tributación simple no estarían sometidos al impuesto de renta presuntiva, de conformidad con el artículo 67 que modifica el artículo 188 del ET. 
estado, está y estará supeditada a la necesidad financiera del gobierno del cuatrienio para cada ejecución presupuestal.

Pero más allá de la necesidad de reformar el sistema tributario por una insuficiencia de caja, está el requerimiento jurídico fundamentado en las exigencias constitucionales para la realización del Estado social de derecho (ESD), no cualquier tipo de Estado, ni con cualquier tipo de medio. Es un Estado que respeta los principios jurídicos como la libertad, la igualdad, la multiculturalidad, el trabajo, la propiedad privada, la vida digna y - sobre todo - la justicia, de modo que cualquier medio que se use para lograr sus fines no puede anular o transgredir los derechos y garantías mínimas, tal es el caso de la norma tributaria cuando se usa más como instrumento de financiación que de redistribución. El derecho tributario debe abanderar la construcción jurídica de un sistema tributario justo, con impuestos equitativos, progresivos que se ajusten a la realidad objetiva y subjetiva del obligado a dar, dónde los impuestos solo existan y se reclamen allí dónde se debe, puede y se tiene que exigir, sólo así la imposición tributaria será neutral y contribuirá con justicia al desarrollo, de lo contrario puede acrecentar la brecha social, dejando al pobre más miserable y al rico lo convertiría en centro de acumulación.

Desde aquí, la preocupación por el estudio de la estructura de los impuestos directos como el impuesto a la renta tanto para la personas naturales como para las personas jurídicas, pues en él es, y debe ser, más manifiesta la función redistributiva, ya que debe recaer sobre el residual de riqueza generado por una actividad, o por la riqueza que se posee en un momento determinado (patrimonio) y no sobre el consumo o actos aislados, por ende, se debe buscar que por lo menos este tipo de impuestos cumplan con el presupuesto jurídico de perseguir la riqueza donde se encuentre, encontrarla objetivamente, gravarla y exigir efectivamente el impuesto.

\section{ESTRUCTURA DEL IMPUESTO SOBRE LA RENTA}

La estructura del impuesto sobre la renta en Colombia no se articula en una ley en particular, como en Chile o Perú ${ }^{14}$ u otros países latinoamericanos; ésta se encuentra dispersa en el conjunto de normas que se exponen

14 En Chile el impuesto sobre la renta está contenido en el Decreto Ley 824, en Perú el Texto Único Ordenado de la Ley del Impuesto a la Renta está contenido en el Decreto Supremo núm. 179-2004-EF. 
en el Estatuto Tributario, que pese a la recopilación realizada mediante el Decreto Único Tributario (DUT), ${ }^{15}$ sigue siendo un disgregado de normas tributarias por poco confusas, repetitivas y hasta contradictorias. El impuesto genéricamente es de período, abarcando la sumatoria de ingresos totales durante un año calendario, y recae sobre las rentas de fuente nacional generadas de forma temporal o transitoria, de conformidad con el artículo 24 ET; por lo demás, el impuesto sobre la renta para las personas naturales y las personas jurídicas se cimienta sobre una estructura diferencial.

Para las personas naturales, la tarea resulta mucho más compleja, en tanto la determinación de la carga impositiva se desprende, en primer lugar, de la identificación del hecho generador, constituido por la percepción de ingresos susceptibles de incrementar el patrimonio neto que no se encuentren claramente exceptuados, dentro de ellos: salarios y/o rentas de trabajo, rendimientos derivados de actividades económicas (profesiones liberales o empresariales), los rendimientos que genere el propio patrimonio (intereses), gananciales, herencias, donaciones.

Determinado el hecho generador, se debe identificar la categoría de sujeto pasivo, que de acuerdo con los artículos 7o. al 11 del ET, son las personas físicas, sucesiones ilíquidas, estableciendo que los cónyuges se gravan de forma individual, y que se debe entender como residencia para efectos fiscales; sin embargo, la clasificación del sujeto puede ser la misma o no, ya por incremento o disminución de patrimonio o renta del contribuyente o por simple disposición normativa como sucedió con la Ley 1607/2012 ${ }^{16}$ y $1739 / 2014$.

Seguidamente, se debe calcular la base imponible, cuantificando la sumatoria de ingresos totales del período, acumulándoles de acuerdo con la fuente en cada una de las cédulas, para luego aminorar las rentas excluidas, no gravadas y exentas que, como se ha expuesto, definitivamente período a período no son las mismas.

15 Por medio del Decreto 1625 en el que se expide el Decreto Único Reglamentario en materia tributaria (Diario Oficial núm. 50023 del 11 de octubre de 2016), se consolidó el DUT, buscando racionalizar y simplificar a través de la compilación de normas de la misma naturaleza, pero dada el alto volumen de producción normativa, si bien fue un comienzo, aún queda mucho camino por recorrer.

16 A raíz de la reforma tributaria Ley 1607 de 2012, el gobierno tuvo que aclarar los criterios de clasificación dada la confusión generada, por tanto, a través del Decreto 3032 emitió definiciones para precisar las categorías de empleado, trabajador por cuenta propia y otros, hasta que se eliminó de manera definitiva con la Ley 1819 de 2006.

Esta obra está bajo una Licencia Creative Commons

Atribución-NoComercial-SinDerivar 4.0 Internacional, IIJ-UNAM.

Boletín Mexicano de Derecho Comparado, núm. 155, mayo-agosto de 2019, pp. 721-756. 
Tasada la renta líquida gravable a cada cédula se le debe aplicar la tarifa, así: a) para las rentas clasificadas, tanto en la cédula de rentas de trabajo y la cédula de pensiones, se aplicará el rango tarifario establecido en el artículo 241.1 ET. La disposición normativa fija cuatro rangos tarifarios, iniciando con tarifa cero $(0 \%)$ para las rentas liquidas gravables que, calculadas de acuerdo con las normas aplicables y vigentes, sean menores a $1090 \mathrm{UVT}^{17}{ }^{17}$ los siguientes rangos fijan tarifas marginales del 19\%, 28\% y una máxima del 19\%; b) para las rentas líquidas gravables declaradas tanto en la cédula de rentas no laborales como las de capital, el legislador fijó seis rangos de tarifas marginales, iniciando con una cero $(0 \%)$ y una tarifa máxima del $35 \%$, con rangos de renta progresivos comenzando con 600 UVT y las superiores a 4000 UVT; ello significa que las personas naturales que registren rentas y declaren por estos conceptos iniciarán a tributar si la renta líquida gravable es superior a $\$ 19,115,400$, y c) para dividendos o participaciones recibidas por personas naturales residentes, el artículo 242 ET fija tres rangos de rentas con su respectiva tarifa marginal, partiendo en rentas líquidas gravables superiores a 600 UVT y finalizando con aquellas superiores a 1000 UVT, y una tarifa marginal inicial de 5\% y 10\%. Por otra parte, señala que los dividendos y participaciones pagados o abonados en cuenta de las personas naturales residentes, derivado de la distribución de utilidades gravadas de acuerdo con la metodología del artículo 49, parágrafo dos, estarán gravados a una tarifa general del 35\%.

Por su parte, para las personas jurídicas, normativamente la imposición recae sobre las sociedades con residencia fiscal, distinguiendo algunas sociedades del régimen fiscal especial, ${ }^{18}$ como se mencionó el apartado precedente. ${ }^{19} \mathrm{El}$ hecho imponible lo configuran los ingresos de fuente nacional derivados de la explotación, venta de bienes materiales o inmateriales, y

17 La UVT vigente y aplicable para las obligaciones tributarias administradas por la UAE DIAN para 2017 se fijó en \$31.859, el 21 de noviembre de 2016, mediante la Resolución 71, se fijó el valor de la Unidad de Valor Tributario (UVT) aplicable para 2017. Así, la renta líquida gravable, objeto del gravamen para las cédulas de rentas de trabajo y la cédula de pensiones, inicia con un valor igual o superior a $\$ 34,726,310$.

18 No son contribuyentes todos los entes territoriales, corporaciones autónomas y de desarrollo sostenible, áreas metropolitanas, Sociedad Nacional de Cruz Roja Colombiana y su sistema federado, las superintendencias y las unidades administrativas especiales, de acuerdo con el artículo 22 ET.

19 Artículos 12 al 19 del ET. 
la prestación de servicios dentro del territorio nacional. ${ }^{20} \mathrm{El}$ cálculo de la base imponible, en términos generales, está contenido en el artículo 26 ET, los ingresos brutos conformados por la suma total de los ingresos percibidos en el período gravable, susceptibles de producir un incremento patrimonial en el momento de su percepción, no exceptuados ni excluidos, se le restan los descuentos, rebajas y devoluciones, con lo cual se obtendrá el ingreso neto; al ingreso neto se le sustraen todos los costos imputables para su realización, para obtener la renta bruta a la que se restan las deducciones para llegar a la renta líquida a la cual se le aplica la tarifa general del 33\%, salvo que sean sociedades de régimen especial o se encuentren en zona franca, ${ }^{21}$ para las que se aplica una tarifa diferencial del $20 \%$, o sociedades del sector hotelero sobre las que recae una tarifa del 9\%.

Así, el régimen normativo vigente y aplicable en Colombia, por sí mismo, imprime un desequilibrio desde la estructura impositiva, pues ha de recordarse que la simplicidad es un aditamento de la claridad jurídica, que debe ser una de las características en la configuración de un sistema tributario equitativo y justo, pues como se ha expuesto, las normas definitorias de la estructura tributaria para las personas naturales son abundantes, dispersas, muchas son normas remisorias, complejas y ambiguas. De otra parte, el proyecto de reforma tributaria mal denominado "Ley de Financiamiento" que cursa actualmente en el Congreso, retorna al antiguo cálculo de renta global, cambia completamente el monto y el tipo de deducciones, conjugado con un aumento de la tarifa nominal, reformas que imprimen mayor presión tributaria a las personas naturales.

Por otro lado, el proyecto de ley plantea para las sociedades una disminución de la tarifa en tres puntos porcentuales en los siguientes años, un aumento de las deducciones, la reincorporación de los descuentos tributarios y los contratos de estabilidad jurídica, ampliar la gama de rentas exentas para sectores de economía naranja, entre otras reformas. En ambos casos, las reformas propuestas son una transformación parcial, pero pro-

20 Respecto a las sociedades extranjeras, el artículo 20 ET dispone que, salvo las excepciones previstas en tratados internacionales, las demás sociedades extranjeras tributarán por sus rentas de fuente nacional.

21 El artículo 240.1 ET, establece como excepción los nuevos usuarios de zonas francas del municipio de Cúcuta entre enero de 2017 y diciembre de 2019, para los cuales se mantiene la tarifa del $15 \%$, condicionada a dos características: i) que las zonas francas cuenten con más de 80 hectáreas, y ii) garantía de que la nueva zona franca va a tener más de 40 usuarios, ya sean empresas nacionales o extranjeras. 
funda, al impuesto sobre la renta, imponiendo una mayor carga tributaria a las personas naturales e indiscutiblemente disminuyendo la carga tributaria para las empresas, vía tratamientos preferenciales representados en beneficios tributarios que arropan el impuesto sobre la renta con un halo de inequidad tributaria.

\section{EL IMPUESTO DE RENTA Y EL GASTO TRIBUTARIO}

Expuesta de manera general la evolución y la estructura del impuesto de renta en Colombia, tanto para las personas naturales y las sociedades, son variadas las observaciones jurídicas que se han realizado por detractores y defensores.

Ante la tributación para personas naturales, Piza Rodríguez (2014) encuentra claramente inequitativas e injustas las disposiciones con normas que en poco o nada contribuyen a la equidad y la simplicidad del sistema; Domínguez (2014) sostiene que la Ley 1607 complejizó la gestión tributaria en términos del control; Farné y Rodríguez (2014) en un análisis del efecto de la Ley 1607 sobre el empleo, exponen cómo una mayor proporción de pago de impuestos es transferido a los trabajadores vía menores salarios y en caso de reducción impositiva tienen la misma consecuencia, por tanto el objetivo de generar mayor empleo difícilmente se alcanza, encuentran una sobreestimación del efecto distributivo por las estridentes inequidades de la norma que desestimulan la generación efectiva de nuevos puestos de trabajo; Caicedo Tribín (2014), al evaluar los efectos de ésta misma ley desde la perspectiva del principio de eficiencia, señala que la norma careció de un estudio previo riguroso, dificultando el cumplimiento de las obligaciones por la complejidad de los procesos formales, la deficiente, indeterminada y, por tanto, ambigua redacción de los preceptos normativos que obligó al uso excesivo de decretos reglamentarios.

Así, doctrinantes, académicos y respetados juristas confluyen en el señalamiento de un sistema tributario que se soporta en la emisión de leyes fragmentarias con perspectivas de corto plazo, carentes de un análisis previo de causas, efectos y alternativas, ajustadas casi de manera exclusiva para suplir las necesidades financieras del gobierno en turno; por tanto, de modificación constante que demandan un esfuerzo legislativo para la precisión o aclaración de la norma, o la proliferación de conceptos jurídicos por parte de la Unidad Administrativa Especial de la Dirección de Impuestos y Aduanas Nacionales (UAE DIAN), afectando severamente la 
estabilidad jurídica, la confianza del contribuyente y, por ende, uno de los principios de cualquier sistema tributario, la seguridad jurídica de los obligados a contribuir.

Veamos el siguiente ejemplo: la sentencia del 15 de abril de 2015 de la Sección Cuarta del Consejo de Estado Colombiano (CECcol), al resolver el caso administrativo Cementos El Cairo S.A. vs. UAE DIAN (Sentencia 200404972/2015). El problema jurídico fue la procedibilidad de la deducción de pérdidas acumuladas sobre la renta líquida gravable del año gravable 1999, sin importar que se generara una nueva pérdida fiscal según concepto 47433 del 20 de mayo de 1990, o la aplicación de la deducción sólo hasta el margen de la renta líquida del período según concepto 020727 del 6 de marzo de 2000, publicado en diciembre de 1999. El contribuyente hizo uso del primer concepto y la UAE DIAN aplicó el segundo; por ende, requirió al contribuyente para realizar la liquidación oficial de revisión, modificando la deducción y el impuesto, confirmando su decisión a través de la notificación de Resolución, previa interposición del recurso de reposición de Cementos Cairo S.A.

En el análisis del caso, la Sala recordó la fuerza vinculante de los conceptos de la UAE DIAN de conformidad con el artículo 264 de la Ley 223 de 1995, reiterada en la Sentencia de la Sección Cuarta de este misma órgano, de mayo de 2012, expediente 73001-23-31-000-2009-00439-01 (18 839), la cual dispuso que la actuación de los contribuyentes con base en los conceptos jurídicos escritos por la Subdirección Jurídica de la UAE DIAN, pueden sustentar actuaciones en vía gubernativa y jurisdiccional durante el tiempo que los conceptos se encuentren vigentes, sin que puedan ser objetadas, dejando claro que cualquier cambio de posición por parte de la UAE DIAN debía ser publicado. Igualmente invocó la irretroactividad de la ley para los impuestos de período, tal cual lo dispone el artículo 338 superior. Bajo estas consideraciones jurídicas, la Sala precisó que si bien el concepto 020727 del 6 de marzo de 2000 había sido publicado en el mes de diciembre de 1999, éste solo entraba en vigencia para el año siguiente en razón de que el impuesto de renta es un impuesto de periodo y los efectos de una norma para este tipo de impuestos no se podían retrotraer en el tiempo, porque ello lesionaba el principio tributario de irretroactividad de la norma, afectando la seguridad jurídica, la confianza de la ley y la certeza de las consecuencias jurídicas, los principios de buena fe y confianza legítima, confirmando así la liquidación privada de Cementos El Cairo S.A. (Cementos El Cairo S.A. v. UAE Dirección de Impuestos y Aduanas Nacionales, 2004). 
Este tipo de situaciones jurídicas serían evitables si la legislación tributaria colombiana no fuera una colcha de retazos, que se tiene que pespuntear al amparo de las necesidades presupuestales de cada gobierno, generando dispersión normativa, contrariedad en la interpretación y aplicación de la norma tributaria, afectando directamente la seguridad jurídica y, por tanto, la justicia del sistema. Pues como se ha expuesto, el impuesto de renta ha sido objeto de múltiples ajustes normativos, que han erosionado la base imponible y han quebrantado el principio de equidad tributaria, a través del aumento o disminución de la tarifa marginal, incremento o reducción de la base imponible por medio de incentivos a la inversión, deducciones aplicables a ciertas actividades, exenciones, descuentos e, incluso, amnistías.

La abultada producción normativa que modifica los elementos de la imposición la vuelven compleja; la constante creación, modificación y eliminación de beneficios tributarios (descuentos, deducciones, exenciones) desequilibran, día a día, la ya desbalanceada distribución de la carga tributaria, desplazando la balanza con mayor rigor hacía las personas naturales y pequeños contribuyentes, pues de alguna forma se debe compensar el menor recaudo que genera el gasto tributario.

Así, la tarea de liquidar el impuesto es compleja y dota la imposición de ineficiencia, pues cuanto más enrarecida sea la depuración de la base imponible, tanto o más lo será la liquidación de la alícuota, facilitando la configuración de figuras jurídico-contables al margen de la norma que abre paso a la elusión o el simple abuso del derecho e incumplimiento del mismo con el no pago del tributo, la evasión, situaciones muchas veces invisibles a la administración de impuestos UAE DIAN.

En este sentido, Bautista, en un análisis de la distribución del impuesto de renta en Colombia para el periodo 1990 a 2002 y su contribución a la equidad, exponía cómo las reformas tributarias se habían enmarcado en una lógica devastadora en el sistema tributario, creando tratamientos preferenciales sin control alguno de las exenciones y su costo fiscal (Bautista, 2011: 57-61), costo que sólo fue cuantificado desde 2004 por la UAE DIAN en cumplimiento del artículo 87 de la Ley 788 de 2002, ${ }^{22}$ concor-

22 Ley 788, por la cual se expiden normas en materia tributaria y penal del orden nacional y territorial; y se dictan otras disposiciones. Diario Oficial núm. 45046 del 27 de diciembre de 2002. 
dante con la Ley 819 de $2003^{23}$ que ordenó la inclusión de la estimación del gasto fiscal en el marco fiscal de mediano plazo. La situación se agrava con el ausente control político por parte del Congreso de la República limitado al control de la legalidad, descuidando la legitimidad normativa, lo que obstaculiza un verdadero examen y ajuste de los impuestos a los principios constitucionales, entre ellos la justicia y los principios de carácter tributario promulgados en el artículo 363: equidad, eficiencia, progresividad y no retroactividad, que en conjunto reclaman la justicia de los tributos para cada uno de los contribuyentes, en razón de su capacidad objetiva y subjetiva de dar, sin lesionar las condiciones más básicas como el mínimo vital, la dignidad, la libertad y la capacidad de decisión.

Actualmente, en Colombia son aplicables tarifas impositivas diferenciales para las sociedades: $20 \%$ para las sociedades de zonas francas y para las empresas de régimen tributario especial, fundaciones, corporaciones, asociaciones y entidades sin ánimo de lucro que cumplan las condiciones normativas para pertenecer a éste régimen, ${ }^{24}$ y $33 \%$ para el resto de sociedades que no corresponden con ninguna de las categorías descritas, aplicable a partir de 2017; adicionalmente, y pese a que la legislación no incluye la tarifa del $0 \%$, sí establece un régimen tributario excepcional para los no contribuyentes, en donde encajan los entes territoriales (artículo 286 constitucional), los partidos políticos, sindicatos, corporaciones autónomas y otras entidades sin ánimo de lucro establecidas taxativamente por el legislador. La UAE DIAN identifica así, cuatro posibles grupos de acuerdo con la responsabilidad tributaria: i) declarantes-contribuyentes; ii) declarantes-no contribuyentes; iii) no declarantes-contribuyentes, y iv) no declarantes-no contribuyentes (Yori y Bravo, 2004: 6).

A la dispar gama de tarifas se le suman las consideraciones especiales aplicables a cada sector, entre ellos: ${ }^{25}$ i) artículo 158.1 ET, donaciones e in-

23 Ley 819, por la cual se dictan normas orgánicas en materia de presupuesto, responsabilidad y transparencia fiscal y se dictan otras disposiciones. Diario Oficial núm. 45243 del 9 de julio de 2003.

24 La Ley 1819 de 2016, mediante los artículos 140 al 143, modificó el régimen tributario especial condicionándolo, así: i) deben estar legalmente constituidas; ii) el objeto social debe ser de interés general en una o varias de las actividades meritorias establecidas en el artículo 359 del ET, y iii) los aportes no deben reembolsarse y los excedentes no pueden ser distribuidos, conforme lo estipula el artículo 356-1 del ET, precepto modificado por esta misma Ley a través del artículo 147.

25 Se mencionan algunos casos de manera ilustrativa que dan cuenta de los diversos tratamientos fiscales a los que puede optar el obligado tributario, dejando claro que estos 
versión en investigación, desarrollo tecnológico e innovación; ${ }^{26}$ ii) artículo 159 ET, industria petrolera y sector minero; las exenciones tributarias por regiones, como San Andrés y Providencia dispuesto en el artículo 150 Ley 1607 de 2012, la zona del Nevado del Ruíz, y iii) artículo 57 ET, Zonas Económicas Especiales de Exportación (ZEEE), Ley 677 de 2000, más los efectos tributarios derivados de los contratos de estabilidad jurídica amparados bajo la Ley 963 de 2005, que persistirán aproximadamente de 20 a 30 años más, pese a que la ley fue derogada por el artículo 166 de la Ley 1607 de 2012, pero que de ser aprobada la Ley de financiamiento volverían con mayor fuerza.

Genéricamente, la UAE DIAN clasifica en tres grupos los beneficios tributarios que afectan la base gravable: i) ingresos no constitutivos de renta ni ganancia ocasional; ii) deducciones, y iii) rentas exentas; ocasionando una tasa de tributación efectiva diferencial para contribuyentes en condiciones similares, rompiendo el principio de equidad y justicia tributaria, en la medida que cuentan con un número finito pero ampliamente divergente de alternativas contables y jurídicas que conllevan a tratamientos fiscales diferentes, por ende a un menor o mayor impuesto liquidado y pagado, distorsionando la carga impositiva y sus efectos en la economía incidiendo directamente, por una parte, en las decisiones de los agentes económicos y, por otra, entrando en la esfera de los mínimos afectables de las personas naturales, quebrantando así los principios constitucionales de carácter tributario.

El menor recaudo tributario por el uso de algún beneficio tributario otorgado se conoce como el gasto tributario. En Colombia, la cuantificación del gasto tributario respondió a los requerimientos de organismos multilaterales, como el Fondo Monetario Internacional (FMI) y la Organización para la Cooperación y Desarrollo Económico (OCDE) más que a una necesidad interna de control y gestión pública. Un análisis de los estudios presentados por la UAE DIAN desde 2004 hasta 2016 hacen una estimación aproximada del gasto tributario, de acuerdo con las recomen-

no son todos, ni los más importantes, pero se considera proporcionan al lector una muestra de lo expuesto.

26 Para este tratamiento especial debe concordarse los artículos 158.1 y el 256 ET, haciendo observancia de las condiciones y criterios fijados por el Consejo Nacional de Política Económica y Social mediante actualización del documento CONPES 3834, de 2015, en todo caso serán deducibles en el período en que se realicen tales donaciones o inversiones. 
daciones de la OCDE usando el método de cálculo ex-post el cual mide la pérdida del gasto después de implementar el beneficio tributario, sin consideración de las alteraciones que se pueden producir por el cambio de una variable o la combinación de varias (Yori et al., 2015: 10-15).

Este tipo de análisis es estático, escapa a la previsión de los efectos fiscales, económicos y financieros por la restricción, eliminación, aumento o disminución de un beneficio tributario; se expresa en términos de cifras absolutas en proporción del PIB, o en relación con el universo de rentas, como la renta exenta, o su participación en el gasto tributario total, o los totales por sector económico. Es un estudio cuantitativo en el cual se evidencian imprecisiones de cálculo, dificultades en la determinación de la tasa nominal para las personas naturales y la tasa efectiva tanto para las personas jurídicas como para las naturales, esto en razón la complejidad derivada del abanico de opciones tributarias que se disponen para aminorar de manera directa tanto la base gravable como el impuesto a pagar, en términos de la tasa efectiva para las personas jurídicas; para las personas naturales, la existencia de la renta exenta por mandato implícito de carácter constitucional, en consideración del artículo lo., reiterado por la Corte Constitucional Colombiana (CCcol), como el mínimo vital y móvil para la existencia de una vida digna (Sentencia SU-995/1999), para lo cual el legislador ha dispuesto unos mínimos exentos (que no se consideran gasto tributario), combinado con una tabla de rangos definidos en los artículos 241 ET ya mencionados que hacen casi imposible llegar a una tasa efectiva única para este tipo de contribuyentes.

En este contexto, es preciso recordar que uno de los pilares del ESD es la igualdad formal y real. La CCcol ha planteado que la igualdad tiene un triple rol: valor, principio y derecho. Como valor es una norma que establece fines para las autoridades creadoras de derecho y el legislador; como principio es una norma que fija un deber específico de aplicación inmediata por el legislador y el juez, y como derecho es subjetiva, concretándose en abstención y acción para la igualdad efectiva en beneficios, oportunidades y obligaciones (Sentencia C-551/2015). Así, en sentido estricto la igualdad tributaria se debería evaluar, ponderar y demostrar, a través de una justa distribución de la carga fiscal, para ello debe entenderse que los derechos y obligaciones emanan en el mismo sujeto en un universo múltiple de sujetos, que deberán recibir el mismo trato o un trato diferencial de acuerdo

Esta obra está bajo una Licencia Creative Commons

Atribución-NoComercial-SinDerivar 4.0 Internacional, IIJ-UNAM.

Boletín Mexicano de Derecho Comparado, núm. 155, mayo-agosto de 2019, pp. 721-756. 
a la relación de similitudes y diferencias en cumplimiento del principio "tertium comparationis".

Gallego Peragón (2013: 130-155) planteaba, por ende, que la igualdad va más allá de la simple generalidad, equilibrando y corrigiendo las desigualdades sociales generadas dentro del sistema económico, tratando igual a los iguales y desigual a los desiguales, suprimiendo cualquier discriminación o arbitrariedad contraria a derecho, exigiendo el tributo donde hay capacidad de dar, función financiera; y transfiriendo recursos para dar allí donde no hay capacidad económica, función redistributiva. Gallo (2011: 128-133) entiende la igualdad no sólo como la equivalencia formal de trato, sino como una regla esencial y autárquica de razonabilidad, heredada y congruente, predominante sobre cualquier otro criterio de distribución de las cargas públicas, por lo tanto, la configuración de la norma tributaria justa debería obedecer al interés general, evidenciado a través del presupuesto y la individualización del sujeto, reconociendo, entre otras, su capacidad contributiva.

Pérez Ayala (2008: 47-55) evidencia desde la evaluación de la justicia del reparto de la carga tributaria "función redistributiva", una vinculación estrecha entre la justicia y la eficacia recaudatoria del sistema para la materialización del ESD, debería por lo tanto existir un adecuado control de los gastos públicos, examinando su intensidad, equidad y eficiencia. Si bien, existe el deber de contribuir con los gastos públicos, el reparto de la carga debe estar precedida por un criterio de justicia distributiva, que presupone un derecho ciudadano a la equidad de los gastos públicos.

La igualdad tributaria no admite tratamientos tributarios diferenciales, en razón de intereses políticos, económicos o individuales, en tal virtud no deberían existir exenciones, deducciones, descuentos o amnistías de ningún tipo y de existir, éstos deben tener un fundamento jurídico ajustado a los máximos esenciales perseguidos por el texto constitucional: convivencia, trabajo, igualdad, libertad, paz y vida digna, principios que se fundamentan en la justicia, tal cual se extracta del preámbulo del texto constitucional. Así, prima facie cualquier beneficio tributario desde una perspectiva jurídica, debe sustentarse en la concreción de los principios que materialicen el Estado constitucional.

Pero innegablemente cualquier beneficio tributario es un tratamiento diferenciado o preferencial que, prima facie, rompe el principio de igualdad, por ende, el principio de generalidad de los impuestos e involucra la 
lesión de otros principios, como la progresividad, capacidad económica y la eficiencia. Es una suerte de tratamiento discriminatorio, al otorgar ventajas fiscales a determinados sujetos, aminorando su carga fiscal (De Juan, 2010: 95-104). Sin embargo, los beneficios pueden buscar objetivos que involucren la materialización de otros principios constitucionales que el Estado considera prioritariamente deseables, situación que genera una colisión de principios jurídicos expresados a través de casos complejos que demandan un mayor esfuerzo del derecho. La cuestión es: ¿Cómo desde el derecho tributario se puede dar solución adecuadamente a estos casos? No existe una respuesta consensuada al respecto, pero una de las alternativas (a la que me adhiero con ciertas objeciones) es la de Robert Alexy (2005), quien plantea que cuando se contraponen derechos que representan principios jurídicos para alcanzar un objetivo, la solución no es única, pero la decisión jurídica debe ser práctica, argumentada y debería soportar el test de razonabilidad evaluado en sus tres tópicos: $i$ ) adecuación de medios al fin perseguido; ii) la necesidad de los medios seleccionados al logro del fin, y iii) proporcionalidad medio a fin; es decir, el principio satisfecho por el logro del fin no debe sacrificar principios constitucionales más relevantes.

Dicho esto, cualquier beneficio tributario en sacrificio del principio de igualdad tributaria debe beneficiar otro(s) principio(s) de mayor talante jurídico, pero en Colombia este requisito jurídico parece diluirse en las discusiones del Congreso. La exposición de motivos de los proyectos de ley que dan origen a las exenciones, deducciones, descuentos y amnistías tributarias se han debatido y justificado desde objetivos estrictamente económicos, entre ellos: incentivar las zonas afectadas por desastres ambientales (Ley 218 de 1995), incentivar el desarrollo de regiones (Ley 677 de 2000), incentivar la inversión extranjera (Ley 963 de 2005), contratos de estabilidad jurídica, la generación de empleo (Ley 1429 de 2010), o mejorar el recaudo a través de amnistías tributarias (artículo 55 de la Ley 1111 de 2006), por citar algunas; que si bien, de alguna manera su origen se ancló en un objetivo social loable, a la postre han resultado inapropiados en la consecución del mismo fin, generando mayores desajustes en la distribución de la carga tributaria.

Aunado a ello, el artículo 154 constitucional dispone que, las normas que decretan exenciones de impuestos, contribuciones o rentas nacionales, son iniciativas legislativas exclusivas del gobierno y que todos los proyectos de ley relativos a los tributos inician su trámite en la Cámara de Repre-

Esta obra está bajo una Licencia Creative Commons

Atribución-NoComercial-SinDerivar 4.0 Internacional, IIJ-UNAM.

Boletín Mexicano de Derecho Comparado, núm. 155, mayo-agosto de 2019, pp. 721-756. 
sentantes. El control constitucional de este tipo de normas no es previo ni automático, generalmente se da por vía de acción; por excepción se hace control previo cuando el Ejecutivo presenta objeciones al proyecto de ley aprobado por el Congreso, pero éste no es un control integral pues se limita a los aspectos objetados por el presidente, para que lo sea, el Ejecutivo deberá haber objetado todo el proyecto, situación muy poco probable. Ésta es una de las razones por las cuáles las normas tributarias, y en especial las que decretan beneficios tributarios, carecen de un estudio previo riguroso y su control se ajuste más a los requerimientos políticos, financieros o económicos del gobierno que los jurídicos, para el caso los principios materiales de la tributación justa.

No se desconoce, existen estudios, pero son posteriores, parciales y de índole financiero, enfocados en ciertos efectos de algunas leyes; por ejemplo, la generación de empleo de la Ley $1429^{27}$ o la Ley 963 de $2005,{ }^{28}$ pero poco o casi nada se ha dicho de la distorsión ocasionada a los principios jurídicos del sistema tributario. Esto en razón de que generalmente el control constitucional se da cuando algún ciudadano preocupado o afectado directamente por una norma en concreto, acciona y reclama sobre los derechos que cree han sido lesionados, fraccionándose el control con decisiones sólo sobre aquello que se reclama; por mencionar algún ejemplo, la demanda de inconstitucionalidad de los artículos 21 y 22 de la Ley 1607, de 2012, interpuesta por Diego Quiñonez, por violación a los principios de legalidad y equidad tributaria porque la norma acusada no permitía la compensación de pérdidas en el Impuesto Sobre la Renta para Equidad (CREE). En el análisis sólo prosperó el segundo cargo, el primero no cumplió con los requisitos mínimos, como son: indicar con precisión el objeto demandado, el concepto de la violación, y la competencia de la Corte. El órgano encontró que la exclusión de la compensación afectó gravemente un principio constitucional, no existiendo otro beneficiario, generó rasgos confiscatorios en el gravamen e impactó el sistema tributario por su carácter regresivo; por tanto, declaró la exequibilidad del precepto a través de un fallo integrador,

27 El primer estudio formal por parte del gobierno lo realizó la UAE DIAN, fue publicado en 2013 limitándose a la mención de las empresas que se acogieron a los beneficios otorgado por la Ley 1429, cumpliendo con los requisitos, sin dar evidencia alguna de la generación de empleo, el cumplimiento del objetivo (UAE DIAN, 2011: 34).

28 Sobre la Ley 963, no existe un estudio oficial por parte del gobierno que estime los efectos, se publica una lista de los contratos celebrados y en ejecución en la página del Ministerio de Industria Comercio y Turismo (MinCit, 2016). 
tratando de solventar la omisión legislativa relativa de la norma, en el entendido de que se podrían compensar las pérdidas incurridas en el CREE (Sentencia C-291/2015). Cómo ésta, se podrían citar varias demandas de la misma ley, u otras leyes de carácter tributario, que la alta Corte ha tenido que resolver a través de fallos de exequibilidad o inexequibilidad, ocasionando modificaciones normativas a pedazos que hacen aún más complejo el sistema tributario.

Por otra parte, el análisis de los informes del gasto tributario presentados por la UAE DIAN, desde 2004 hasta 2014 deja aún muchos más cuestionamientos jurídicos sobre el ajuste de los beneficios tributarios a los principios tributarios. La tabla 1 presenta, en resumen, algunas cifras expuestas en dichos reportes.

\section{TABLA 1}

COSTO FISGAL DE LOS PRINCIPALES BENEFICIOS TRIBUTARIOS DEL IMPUESTO DE RENTA. TOTAL DE DEGLARANTES, EXPRESADO EN MILES DE MILLONES DE PESOS

\begin{tabular}{|c|c|c|c|c|c|c|c|c|c|c|c|}
\hline $\begin{array}{c}\text { Tipo de } \\
\text { beneficios }\end{array}$ & 2004 & 2005 & 2006 & 2007 & 2008 & 2009 & 2010 & 2011 & $2012^{*}$ & $2013^{*}$ & $2014^{* *}$ \\
\hline Deducciones & 0,816 & 1,115 & 1,819 & 3,125 & 3,944 & 4,079 & 3,917 & 0,540 & 0,665 & 0,598 & 0,830 \\
\hline $\begin{array}{c}\text { Rentas } \\
\text { externas }\end{array}$ & 1,599 & 2,040 & 2,922 & 2,849 & 3,405 & 3,530 & 4,143 & 4,731 & 3,073 & 5,346 & 5,721 \\
\hline $\begin{array}{c}\text { Descuentos } \\
\text { tributarios }\end{array}$ & 0,075 & 0,078 & 0,191 & 0,288 & 0,378 & 0,516 & 0,496 & 0,753 & 0,702 & 0,883 & 0,948 \\
\hline $\begin{array}{c}\text { Total del } \\
\text { costo fiscal }\end{array}$ & 2,49 & 3,23 & 4.93 & 6,26 & 7,73 & 8,13 & 8,56 & 6,02 & 4,44 & 6,83 & 7,50 \\
\hline \multicolumn{7}{|c|}{ Distribución del costo fiscal según tipo de declarante } \\
\hline $\begin{array}{c}\text { Personas } \\
\text { naturales }\end{array}$ & 0,85 & 0,98 & 1,11 & 1,34 & 1,54 & 1,68 & 1,78 & 1,93 & $\mathrm{ND}$ & $\mathrm{ND}$ & $\mathrm{ND}$ \\
\hline $\begin{array}{c}\text { Personas } \\
\text { jurídicas }\end{array}$ & 1,64 & 2,26 & 3,82 & 4,92 & 6,19 & 6,45 & 6,77 & 4,10 & 4,44 & 4,99 & 5,54 \\
\hline $\begin{array}{c}\text { Total del } \\
\text { costo fiscal }\end{array}$ & 2,49 & 3,23 & 4,93 & 6,26 & 7,73 & 8,13 & 8,56 & 6,02 & $\mathrm{ND}$ & $\mathrm{ND}$ & $\mathrm{ND}$ \\
\hline \multicolumn{7}{|c|}{ Costo fiscal como porcentaje del PIB } \\
\hline $\begin{array}{c}\text { Personas } \\
\text { naturales }\end{array}$ & $0,02 \%$ & $0,02 \%$ & $0,02 \%$ & $0,02 \%$ & $0,04 \%$ & $0,33 \%$ & $0,32 \%$ & $0,31 \%$ & $\mathrm{ND}$ & $\mathrm{ND}$ & $\mathrm{ND}$ \\
\hline $\begin{array}{c}\text { Personas } \\
\text { jurídicas }\end{array}$ & $0,86 \%$ & $0,88 \%$ & $1 \%$ & $1,68 \%$ & $1,28 \%$ & $1,28 \%$ & $1,25 \%$ & $0,67 \%$ & $0,67 \%$ & $0,59 \%$ & $1,03 \%$ \\
\hline$\%$ del PIB & $0,9 \%$ & $0,9 \%$ & $1 \%$ & $1,7 \%$ & $1,3 \%$ & $1,6 \%$ & $1,6 \%$ & $1 \%$ & $\mathrm{ND}$ & $\mathrm{ND}$ & $\mathrm{ND}$ \\
\hline
\end{tabular}

Esta obra está bajo una Licencia Creative Commons

Atribución-NoComercial-SinDerivar 4.0 Internacional, IIJ-UNAM.

Boletín Mexicano de Derecho Comparado, núm. 155, mayo-agosto de 2019, pp. 721-756. 
Esta revista forma parte del acervo de la Biblioteca Jurídica Virtual del Instituto de Investigaciones Jurídicas de la UNAM

\begin{tabular}{|c|c|c|c|c|c|c|c|c|c|c|c|}
\hline $\begin{array}{l}\text { Tipo de } \\
\text { beneficios }\end{array}$ & 2004 & 2005 & 2006 & 2007 & 2008 & 2009 & 2010 & 2011 & $2012^{*}$ & $2013^{*}$ & $2014^{* *}$ \\
\hline \multicolumn{12}{|c|}{ Tasas base del impuesto de renta } \\
\hline \multicolumn{12}{|l|}{$\begin{array}{l}\text { Personas } \\
\text { naturales }\end{array}$} \\
\hline $\begin{array}{c}\text { Tasa } \\
\text { nominal }\end{array}$ & 7,60 & 7,40 & 7,30 & 7,20 & 7,20 & 6,90 & 7,10 & 7,40 & ND & ND & ND \\
\hline $\begin{array}{c}\text { Tasa } \\
\text { efectiva }\end{array}$ & ND & ND & ND & ND & ND & ND & ND & ND & ND & ND & ND \\
\hline \multicolumn{12}{|l|}{$\begin{array}{l}\text { Personas } \\
\text { jurídicas }\end{array}$} \\
\hline $\begin{array}{c}\text { Tasa } \\
\text { nominal }\end{array}$ & 38,50 & 38,5 & 38,5 & 34 & 34 & 33 & 33 & 33 & 33 & 25 & 25 \\
\hline $\begin{array}{c}\text { Tasa } \\
\text { efectiva }\end{array}$ & 26,40 & 29,3 & 30,5 & 26 & 24,8 & 23,5 & 24,1 & 28 & 28 & 20,9 & 20,4 \\
\hline
\end{tabular}

ND: Información no disponible en los informes evaluados.

* La información de los años 2012 a 2014 está incompleta porque no hay información sobre las personas naturales.

** Los datos económicos de 2014 son cifras proyectadas por el Ministerio de Hacienda y Crédito Público.

FUENTE: Estudios económicos. Cuadernos de trabajo de la UAE DIAN, desde 2004 a $2015 .^{29}$

Financieramente, se observa cómo las rentas exentas han tenido una mayor participación en el gasto fiscal con una tendencia creciente, registrando un mayor aumento en 2013 y 2014, fruto de las rentas exentas aplicables al CREE. Las deducciones evidencian un crecimiento que se agudiza en 2007 producto de la modificación del 30 al 40\% del beneficio por la inversión en activos fijos reales productivos, según el artículo 68 de la Ley 863, de 2003, eliminada mediante la Ley 143 de 2010, año en que disminuye. En cuanto a los descuentos, ya que estos se restan de manera directa del impuesto liquidado, han sido un tanto más limitados y se han orientado a materias muy particulares, como la inversión en acciones del sector agropecuario que coticen en bolsa (artículo 249 ET), reforestación (artículo $253 \mathrm{ET}$ ), rentas pagadas en el exterior (artículo $254 \mathrm{ET}$ ), entre

29 Esta tabla es un resumen resultante del análisis de los informes sobre gasto tributario presentados por la UAE DIAN, 13 reportes emitidos desde 2004, complementariamente se analizaron otros informes sobre los beneficios tributarios, el primero de 2004 sobre aquellos beneficios aplicables al impuesto de renta, el segundo de 2005 y 2006 sobre beneficios, tanto para el impuesto de renta como el IVA; el tercer informe sobre el efecto de la deducción del 30\% por inversión de activos fijos reales productivos de 2004, publicado en 2006 (véase Parra, 2006: 1-17; Yori y León, 2005: 1-37). 
otras; alcanzando mayor participación en 2013 y 2014 por el mayor uso de los beneficios por parte de los declarantes. Los informes presentaban hasta 2011 la distribución del costo fiscal por tipo de declarante, pero no existe registro de información sobre las personas naturales después de este año, en ninguno de los informes estudiados se da explicación alguna. La ausencia de información sobre el costo fiscal de los beneficios tributarios de las personas naturales distorsiona el total de los mismos años. El costo fiscal en términos del PIB, llegó a un máximo en 2007, con el 1.7\%, y los mínimos se presentaron en 2004 y 2005, con un 0.9\%; en el período 2012 a 2014 este indicador no se puede construir por la ausencia de información mencionada.

¿Por qué es importante esta información desde el punto de vista jurídico? Son muchas las razones, en primera instancia, la información cuantitativa es un indicador de la secuela generada por la multiplicidad de reformas tributarias sucintamente descrita al inicio del documento, da cuenta de la incidencia de los beneficios tributarios en la tasa de tributación efectiva para las personas jurídicas, no de otro modo la tasa promedio de estos once años es de 25.63, con una dispersión de los datos supremamente alta en un rango de variación de 10.1 puntos, que al compararse con la tasa nominal promedio de 33.23, con una dispersión aún mayor en rango de variación es 13.5 puntos, lo cual revela un gran distanciamiento entre lo legislativamente previsto y lo realmente efectuado por el contribuyente.

La separación entre lo normativamente dispuesto y lo normativamente interpretado y aplicado por el contribuyente, queda expuesto en el informe de la UAE DIAN de septiembre de 2015, el cual da cuenta de un intento por determinar la tasa efectiva promedio de tributación para las personas jurídicas para el año fiscal 2013, éste reconoce que la tasa efectiva promedio de tributación en Colombia es alta, alcanzando un aproximado de $61 \%$, pero que el cálculo metodológico encierra grandes distorsiones sectoriales, mencionando los resultados que sobre el mismo aspecto obtuvieron la Fundación para la Educación y Desarrollo (Fedesarrollo), y la Asociación Nacional de Industriales (Andi), con tasas efectivas promedio de 56\% y 58\%, respectivamente (Ávila, 2015: 19). Hasta noviembre de 2018 no se había emitido informe similar por la UAE DIAN, dejando en evidencia las dificultades aquí expuestas, pero sí se emitió uno parcial, presentado como una primera aproximación a la medición del costo de tres beneficios tributarios para las sociedades: i) la disminución de la tasa impositiva; ii) la no 
sujeción al CREE, y iii) costo de los contratos de estabilidad jurídica, para las personas naturales se estima el costo en términos globales.

Las cifras del informe a noviembre de 2018 revelan un incremento del gasto tributario, pasando de 33.4 billones de pesos, equivalentes al $6.2 \%$ del PIB de 2010, a 59.3 billones de pesos, 6.4\% del PIB en 2017; el costo de los contratos de estabilidad jurídica representa un $0.1 \%$ en 2017 , y en cuanto a las personas naturales se presenta solo información porcentual, exponiendo solo un incremento del $0.30 \%$ de 2010 a 2017, alcanzando un 0.70\% del PIB (Ávila, 2015: 13); sin embargo, en el documento se aclara que la información tomada fue la observada en 2016, puesto que para el caso de las personas naturales no se contaba con la información completa. En cuanto a las sociedades, se declara como información provisional (Ávila, 2015: 17); es decir, sería una información parcial, de la cual no se podría sostener nada concluyente aún.

La histórica mutación jurídica por la que ha transitado el impuesto sobre la renta y complementarios, expuesta en el primer capítulo, ha tenido un reflejo directo en la estructura impositiva, sumergiéndolo en un clima de inestabilidad con la consecuente variabilidad de la carga tributaria de un período a otro, con un efecto nefasto en la seguridad jurídica, la certeza y la confianza legítima de los contribuyentes. Más aún, el no presentar información sobre las personas naturales desde 2011, no es más que el reconocimiento del enrevesado universo legislativo al que se enfrentan los contribuyentes, pues ni la UAE DIAN es capaz de construir información medianamente confiable sobre el gasto tributario para este tipo de contribuyentes.

Un cuestionamiento sobreviniente es: ¿cómo entiende o debe entender la norma tributaria y cómo la aplica el obligado a contribuir?, aventuradamente se dirá, como mejor la encuentre el contribuyente. Una normatividad clara de fácil entendimiento y aplicación imprime mayor equidad al sistema tributario, pero eso no sucede en Colombia. En palabras de Ferreiro Lapatza (1998: 23-27), pareciera que el país careciera de una correcta técnica jurídica, dado que el sistema tributario colombiano no es sencillo, su comprensión no es simple, la coherencia normativa es con frecuencia un elemento ausente y como se evidencia es completamente inestable.

$\mathrm{Al}$ respecto, el Centro Interamericano de Administraciones Tributarias (CIAT), sostiene que si bien es cierto que la cuantificación del gasto tributario es importante, es aún más relevante conocer si éstos han sido 
efectivos, si realmente están soportados por el cumplimiento de los objetivos económicos y sociales por los cuales fueron creados, concluyendo, que ello no está claro en América Latina, donde los informes de gasto tributario no son valiosos para la política fiscal; por lo tanto, no tienen incidencia en las reformas tributarias, motivo por el cual proponen un modelo único de reporte que muestre la relación costo beneficio (Pecho, 2014); para la adopción de éste modelo en Colombia sería necesaria la participación tanto de la UAE DIAN como el Ministerio de Hacienda y Crédito Público, el Departamento Nacional de Estadística, y aquellos organismos gubernamentales que tengan a disposición indicadores sociales y económicos, pues estos datos deben ser cruzados con el informe de gasto tributario para determinar, al menos de forma cuantitativa e incipiente, si el objetivo perseguido o deseado por el Estado - "materialización de principios de mayor talante jurídico" en sacrificio de la igualdad tributaria-, se logra, de lo contrario estos deberían racionalizarse o eliminarse porque imprimen de cierta forma un grado de injustica que no debería existir en ningún sistema tributario.

Es preciso recordar, por una parte, que un sistema tributario justo se cimienta en la estabilidad, se alienta en la certeza, erigiéndose sobre la confianza legítima; y por otra, que el impuesto sobre la renta es directo, general, global y sintético; características que lo arropan con la mayor carga de justicia; en consecuencia, no es aceptable la configuración de un sistema normativo ajustado según la maleabilidad de las necesidades financieras del gobierno, que se exterioriza a través de preceptos normativos volátiles que otorgan beneficios tributarios sustentados en buenas intenciones, desconociendo la factibilidad jurídica y fáctica medida desde la relación costo/beneficio, ponderando el sacrificio admisible para el contribuyente, el gobierno y la sociedad en general.

\section{Conclusiones}

Revisada la evolución del impuesto de renta y la estructura vigente en Colombia en perspectiva del gasto tributario, se concluye:

La evolución histórica del impuesto sobre la renta, desde 1918 a 2017, da cuenta de la fragilidad de su marco normativo, afectando no solo la imposición en concreto, sino al sistema tributario, al quebrantar, de un lado los principios materiales de la tributación: eficiencia, progresividad y equidad, 
y por otro, rompiendo los principios formales tributarios: certeza, confianza legítima y seguridad jurídica, mandatos esenciales en la configuración de un sistema tributario justo. En consecuencia, el contribuyente transita por arenas movedizas, y a tientas, que obstaculizan o derriban cualquier intento de visión empresarial a mediano o largo plazo.

Bien lo plantea Larenz en el análisis del derecho justo, es cierto que el legislador demanda tiempo, pues las leyes no se dictan para la eternidad, pero tampoco son de momento. La expedición de una ley se cimienta en una motivación razonada y razonable desde los fines constitucionalmente legítimos y su vigencia debe operar sobre futuro previsible (Larenz, 1985: 29). Sin embargo, en Colombia la emisión normativa ha encontrado fundamento en las necesidades financieras y/o presupuestales del gobierno en turno; por lo tanto, las normas emitidas se han extendido en beneficios tributarios para algunos contribuyentes, o los han restringido para otros, acorde con las políticas regionales, sectoriales o globales que el gobierno haya trazado.

Ante un marco jurídico inestable, confuso, repetitivo y hasta contradictorio se ha dado lugar para la construcción de una gama de alternativas jurídico/contables - figuras que los contribuyentes usan en sede interpretativa del derecho, elusión o en abuso del derecho y evasión - para llegar a una menor base gravable y por tanto a la liquidación de una menor alícuota impositiva, situaciones dificilmente detectables por la administración tributaria (UAE DIAN), en razón de la misma dispersión normativa, lo que conlleva inevitablemente al desplazamiento de la presión fiscal sobre algunos contribuyentes representado en la inequitativa distribución de la carga tributaria.

En el impuesto sobre la renta, normativamente se han establecido tratamientos preferenciales a través de exenciones, deducciones, descuentos y hasta amnistías tributarias, justificadas por objetivos aparentemente loables, como el incentivo a la inversión, la generación de empleo, la reconstrucción de zonas y regiones azotadas por catástrofes ambientales o las condiciones geográficas y la vulnerabilidad de las mismas; pero, los objetivos o fines deben ponderarse desde la relación costo/beneficio, de tal forma que aquello que se busca no exceda los límites de lo jurídicamente admisible y lo fácticamente realizable. Pues si bien, en el derecho tributario el desarrollo de la igualdad se consigue desde el reconocimiento de las desigualdades. Esta máxima solo encuentra aval en la distribución equitativa 
de la carga tributaria, en consideración de la capacidad económica, tasada desde la capacidad contributiva, pues nadie está obligado a lo imposible, en consecuencia, el impuesto sobre la renta debe hacer un llamado general a todos a contribuir con las inversiones y gastos del Estado, pero solo concurrirán aquellos que tengan una manifiesta capacidad contributiva, una aptitud para dar.

En este sentido, el impacto de cualquier beneficio tributario debe estudiarse, analizarse y motivarse desde la finalidad perseguida y la estimación del efecto sobre el universo de contribuyentes. Por lo tanto, si la finalidad es incentivar una zona, región, sector industrial o empresarial, ello no será admisible si para lograrlo se impulsa a la miseria otra zona, región o sector; o si para incentivar la creación de empleo para los jóvenes, se emitiera una ley que permitiera un porcentaje de rentas exentas para los contribuyentes que los contraten, pero se incrementara la tasa impositiva para los pensionados, sin importar el monto de la mesada. No cabe duda que cualquier beneficio tributario, representa un menor recaudo de caja que debe solventarse, compensarse o equilibrarse desde alguna otra fuente, o con otra medida; en consecuencia, la emisión de toda norma que cree, modifique o elimine un beneficio tributario debería ser sometida a un control estricto, bajo la aplicación del principio de proporcionalidad, determinando la necesidad e idoneidad en sentido estricto, examen que permitiría evaluar el adecuado balanceo del efecto del gasto tributario en la justa distribución de la carga tributaria.

En todo caso, la discusión sobre la conveniencia o no de los beneficios tributarios, su efecto fiscal en el manejo de las finanzas públicas y la incidencia directa en la consolidación de una estructura tributaria más justa, es una discusión que siempre estará abierta a las mejores propuestas jurídicas, económicas y sociales.

\section{BibliografíA}

ALEXY, Robert, 2005, "Justicia como corrección”, Doxa. Cuadernos de Filosofia del Derecho, núm. 26.

Ávila MaHEchA, Javier, 2015, “Tarifas efectivas promedio de las personas jurídicas. Año 2013”, Subdirección de Gestión de Análisis Operacional, Dirección de Gestión Organizacional. Disponible en: https://wrere.dian. gov.co/dian/cifras/Cuadernos\%20de\%20Trabajo/Tarifas\%20efectivas\%20pro

Esta obra está bajo una Licencia Creative Commons

Atribución-NoComercial-SinDerivar 4.0 Internacional, IIJ-UNAM.

Boletín Mexicano de Derecho Comparado, núm. 155, mayo-agosto de 2019, pp. 721-756. 
medio $\% 20$ de $\% 20$ las $\% 20$ personas $\% 20$ jur\%C3\%ADdicas $\% 20-\% 20 A n ̃ o \% 20$ 2013.pdf\#search =Tarifas $\% 20$ efectivas $\% 2$ promedio $\% 20$ de $\% 2$ olas $\% 20$ perso nas $\% 20 j u r \%$ C3\%ADdicas $\% 2 E \% 20 A \tilde{n} 0 \% 202013$.

Banco Central De la República, 2016, "Banco de la República incrementa en 25 puntos básicos la tasa de interés para la intervención”, comunicado de prensa. Disponible en: http://wrere.banrep.gov.co/es/comu nicado-18-03-2016.

BAUTISTA, Jairo Alonso, 2011, "Equidad o inequidad tributaria: la distribución del impuesto a la renta en Colombia: 1990-2002", Cuadernos de Contabilidad, vol. 12, núm. 30.

Caicedo Tribín, Camilo Francisco, 2014, "Una aproximación a las modificaciones introducidas por la Ley 1607 de 2012 al régimen de las personas jurídicas desde la perspectiva del principio constitucional de eficiencia", Revista del Instituto Colombiando de Derecho Tributario ICDT, vol. 1, núm. 70 .

Galderón, Valentina y GonzÁLez, Francisco, 2002, "Las reformas tributarias en Colombia durante el siglo XX (II)", Reforma Tributaria. Boletines de Divulgación Económica, núm. 9. Disponible en: https://wrwryumpu. com/es/document/read/14799778/las-reformas-tributarias-en-colombia-duran te-el-siglo- $x x-i i$.

COMISIÓN DE EXPERTOS PARA LA EQUIDAD Y COMPETITIVIDAD TRIBUTARIA, 2015a, "Diagnóstico de los problemas que afectan al sistema tributario colombiano". Disponible en: https://comisionreformatributaria.files. wordpress.com/2015/06/informe-al-ministro-de-hacienda-junio-3-de-2015.pdf.

COMISIÓN DE EXPERTOS PARA LA EQUIDAD Y COMPETITIVIDAD TRIBUTARIA, 2015b, "Informe sobre propuesta de reforma al régimen tributario especial (RTE) para las asociaciones, fundaciones y corporaciones (A, $\mathrm{F}_{\text {y }} \mathrm{G}$ ) constituidas como entidades sin ánimo de lucro (ESAL)". Disponible en: https://comisionreformatributaria.files.wordpress.com/2015/09/segun do-informe-comisic3b3n-expertos-equidad-y-competitividad-tributaria-final.pdf.

COMISIÓN DE EXPERTOS PARA LA EQUIDAD Y COMPETITIVIDAD TRIBUTARIA, 2015c, "Informe Final presentado al ministro de Hacienda y Crédito Público". Disponible en: https://comisionreformatributaria.files.word press.com/2015/03/informe-final-de-la-comisiocc81n-versiocc81n-final2.pdf.

Departamento Nacional De Planeación, 2015, "Plan Nacional de Desarrollo 2014-2018. Todos por un nuevo país”. Disponible en: https:// 
colaboracion.dnp.gov.co/CDT/PND/PND\%202014-2018\%20Tomo\%201\% 20internet.pdf.

Direcaión de Impuestos y Adunas NaGionales, 2013, "Primer informe sobre la aplicación de la Ley 1429 de 2010, cifras y estimación del costo fiscal año gravable 2011". Disponible en: https://wrere.dian.gov.co/ dian/cifras/Cuadernos\%20de\%20Trabajo/Primer\%20informe\%20sobre\%20 la\%20aplicación\%20de\%20la\%20Ley\%201429\%20de\%202010,\%20Ci fras $\% 20 y \% 20$ estimación $\% 20$ del $\% 20$ Costo $\% 20$ fiscal\%20año\%20gravable\% 202011.pdf\#search=Primer\%20informe $\% 20$ sobre $\% 20$ la\%20aplicación $\% 20$ de\%20la\%20Ley\%201429\%20de\%202010.

Domínguez, David Felipe, 2014, "El régimen tributario de las personas naturales después de la Ley 1607 de 2012", Revista de Derecho Privado, núm. 51.

EchavarRía Soto, Juan José, 2001, "Colombia en la década de los noventa: neoliberalismo y reformas estructurales en el Trópico", Cuadernos de Economía, vol. 20, núm. 34.

FARNÉ, Estefano y RoDRíGuez, David Arturo, 2014, "Empleo e impuestos a la nómina en Colombia: Un análisis de los efectos ocupacionales de la Ley 1607 de 2012 de Reforma tributaria", Revista de Derecho Fiscal, núm. 7.

FERREIRO LAPATZA, José Juan, 1998, Ensayos sobre metodología y técnica jurídica en el derecho financiero y tributario, Madrid, Marcial Pons.

FrANCO, Gallo, 2011, Las razones del fisco, trad. de José Andrés Rozas Valdez y José Francisco Cañal, Madrid, Marcial Pons.

Gallego Peragón, José Manuel, 2003, Los principios materiales de justicia tributaria, Granada, Comares.

JuAn CaSADEvalL, Jordi de, 2010, El principio de no discriminación fiscal como instrumento de armonización negativa, Madrid, Aranzadi Thomson Reuters.

Junguito, Roberto y Rincón, Hernán, 2004, "La política fiscal en el siglo XX", Borradores de Economía, núm. 318.

LAREnZ, Karl, 1985, Derecho justo: fundamentos de ética jurídica, trad. de Diéz Picazo, Madrid, Civitas.

LÓPEZ, Mauricio et al., 2011, "La Constitución de 1991 y sus implicaciones en materia tributaria y de equidad. Una aproximación a la medición de la progresividad en Colombia”, Perfil de Coyuntura Económica, núm. 17.

PARRA GARZÓn, Diana Marcela, 2006, "Efecto de la deducción por inversión en activos fijos reales productivos en el impuestos sobre la renta.

Esta obra está bajo una Licencia Creative Commons

Atribución-NoComercial-SinDerivar 4.0 Internacional, IIJ-UNAM.

Boletín Mexicano de Derecho Comparado, núm. 155, mayo-agosto de 2019, pp. 721-756. 
Año gravable 2005", Oficina de Estudios económicos, División de Mediciones Fiscales, DIAN. Disponible en: https://wwredian.gov.co/dian/cif ras/Cuadernos $\% 20$ de $\% 20$ Trabajo/Efecto $\% 20$ de $\% 20$ la\%20deducción\%20por $\% 2$ inversión $\% 20$ en $\% 20$ activos $\% 20$ fijos $\% 2$ reales $\% 2$ productivos $\% 20$ en $\%$ 20 el\%20impuesto $\% 20$ sobre\%20la\%20renta. $\% 20$ Año\%20gravable $\% 202$ 005.pdf.

Pecho Trigeros, Miguel, 2014, "Gastos tributarios en América Latina: 2008-2012”, Centro Interamericano de Administraciones Tributarias, Dirección de Estudios e Investigaciones Tributarias, cuaderno de trabajo núm. 2. Disponible en: http://infofiscal.conare.ac.cr/images/docs/citada/Pe cho_-_2014_-_Gastos_tributarios_en_America_Latina_2008-2012-annotated -1.pdf.

PÉREZ De AyALA, José Luis, 2008, Algunos problemas interpretativos del artículo 31.1. de la Constitución Española en un contexto jurisprudencial, Madrid, Aranzadi Thomson Reuters.

PIZA RoDRÍGUEZ, Julio Roberto, 2014, "Equidad y simplicidad en el impuesto de renta de las personas", Revista de Derecho Fiscal, núm. 7.

Restrepo Salazar, Juan Camilo, 2012, La hacienda pública, Bogotá, Universidad Externado de Colombia.

Werner, Alejandro, 2016, "América Latina y el Caribe: Ajustándose a una realidad más dura", Diálogo a Fondo. El blog del FMI sobre temas económicos de América Latina. Disponible en: http://blog-dialogoafondo.org/? $p=6256$.

YORI PARRA, Gloria et al., 2015, "El gasto tributario en Colombia. Beneficios en el impuesto sobre la renta y CREE-personas jurídicas. Años gravables 2013-2014", Coordinación de Estudios Económicos, Dirección de Gestión de Análisis Operacional, Dirección de Gestión Organizacional. Disponible en: http://wrere.dian.gov.co/descargas/Servicios/OEEDocumen tos/Cuadernos/Gasto_tributario_Colombia_Beneficios_Renta_CREE_2013_ 2014.pdf.

YORI PARRA, Gloria y BRAVO DíAZ, Enrique Javier, 2004, “Los beneficios tributarios en el impuesto sobre la renta en Colombia. Año 2003", Oficina de Estudios Económicos. Disponible en: https://wrere.dian.gov.co/dian/ cifras/Cuadernos\%20de\%20Trabajo/Los\%20beneficios\%20tributarios\%20en $\% 20$ el\%20impuesto $\% 20$ sobre $\% 20$ la\%20renta\%20en\%20Colombia. $\% 20 \mathrm{~A}$ ño\%202003.pdf\#search=Los\%20beneficios $\% 20$ tributarios $\% 20$ en $\% 20$ el\%20i mpuesto\%20sobre\%20la\%20renta\%20en\%20Colombia. 
YORI PARRA, Gloria y LEÓn HERnÁndez, Ivonne Rocío, 2005, "Los beneficios tributarios en el impuesto sobre la renta en Colombia. Año gravable 2004", Oficina de Estudios Económicos. Disponible en: https:// wrwedian.gov.co/dian/cifras/Cuadernos\%20de\%20Trabajo/Los\%20benefi cios $\% 20$ tributarios $\% 20$ en $\% 20$ el $\% 2$ impuesto $\% 20$ sobre $\% 20$ la $\% 2$ renta $\% 20$ en\%20Colombia. $\% 20$ Año\%20gravable\%202004.pdf\#search=Los\%20benefic ios $\% 20$ tributarios $\% 20$ en $\% 20$ el\%20impuesto\%20sobre\%20la\%20renta\%20en \%20Colombia\%2E\%20Año\%20gravable\%202004.k. 